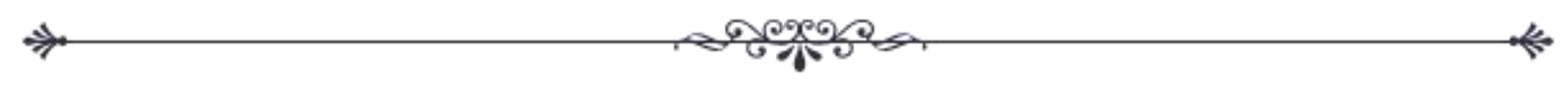

\title{
ПСИХОАОГИЧЕСКИЕ НАУКИ
}

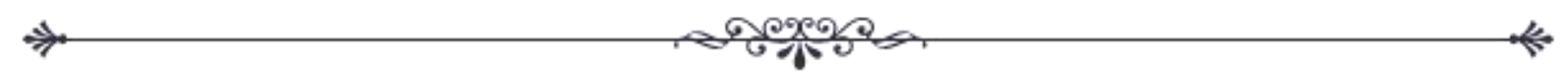

https://doi.org/10.5281/zenodo.3744297

УДК 159.9.072

\section{Демидова И.Г.}

Демидова Ирина Геннадьевна, кандидат психологических наук, доцент, Северный (Арктический) федеральный университет имени М.В. Ломоносова, 163002, Россия, г. Архангельск, набережная Северной Двины, д. 17. E-mail: i.demidova@narfu.ru.

\section{Особенности личностной тревожности у детей младшего подросткового возраста}

Аннотация. Представлены данные об особенностях проявлений личностной тревожности у пятиклассников. Анализируются различные параметры оценки эмоционально-поведенческих расстройств тревожного спектра у младших подростков: тревожность, связанная с личностными особенностями ребенка, с социальными контактами, с ситуациями школьного обучения. Сопоставляются данные, полученные с помощью различных диагностических методик исследования тревожных проявлений младших подростков: многомерная оценка детской тревожности Е.Е. Ромицыной и «Незаконченные предложения» А.В. Микляевой и П.В. Румянцевой. Предложены направления коррекционно-развивающей работы по преодолению личностной тревожности у детей младшего подросткового возраста.

Ключевые слова: младшие подростки, личностная тревожность, тревога в отношениях со сверстниками, тревога в отношениях с родителями, тревога в ситуациях проверки знаний, многомерная оценка детской тревожности, незаконченные предложения, коррекция тревожности.

\section{Demidova I.G.}

Demidova Irina Gennadievna, Candidate of Psychological Sciences, Associate Professor, Federal State Autonomous Educational Institution of Higher Education «Northern (Arctic) Federal University named after M.V. Lomonosov», 163002, Russia, Arkhangelsk, embankment of the Northern Dvina, 17. E-mail: i.demidova@narfu.ru.

\section{Features of personal anxiety in early teens}

Abstract. The data on the features of manifestations of personal anxiety in fifth graders are presented. Various parameters of the assessment of emotional-behavioral disorders of the spectrum of anxiety in younger adolescents are analyzed: anxiety associated with the personal characteristics of the child, with social contacts, with situations of school learning. The data obtained using various diagnostic methods for studying the anxiety manifestations of younger adolescents are compared: a multivariate assessment of child anxiety E.E. Romitsyna and "Incomplete offers" A.V. Miklyaeva and P.V. Rumyantseva. The directions of correctional development work to overcome personal anxiety in children of younger adolescents are proposed. 
Key words: younger adolescents, personal anxiety, anxiety in relationships with peers, anxiety in relationships with parents, anxiety in situations of knowledge testing, multidimensional assessment of child anxiety, unfinished sentences, correction of anxiety.

$\Pi$ ереход обучающихся от начального образования к основному приносит в жизнь детей множество изменений: расширяется социальное окружение, появляются новые предметы, новые учителя, новые способы интеллектуальной деятельности - все это может сопровождаться эмоциональным дискомфортом и внутренней напряженностью подростка. Этот непростой в жизни школьников период характеризуется зарождением и формированием чувства взрослости, появлением новых увлечений, ценностей, трансформацией ведущей деятельности, теперь ориентированной на общение со сверстниками. Повышенная сензитивность младших подростков к неудачам, трудностям, проблемам может провоцировать рост тревожности и стремление детей отказываться от той деятельности, в которой они неуспешны. В результате этих изменений подростки становятся менее успешными в процессе установления отношений со сверстниками и учителями, что также может спровоцировать снижение уровня учебных достижений, осложнить процесс социальной адаптации, привести к школьной дезадаптации [4].

Мы рассматриваем личностную тревожность как устойчивую индивидуальную характеристику, отражающую предрасположенность субъекта к тревоге и предполагающую наличие у него тенденции воспринимать достаточно широкий «веер» ситуаций как угрожающие, отвечая на каждую из них тревожной реакцией. Тревожность воздействует на различные стороны психики. Состояние тревоги обращено в будущее, оно содержит в себе мучительное ощущение беспокойства, настороженность, предвосхищение опасности, неопределенной угрозы. У тревожных людей обостряется стремление к безопасности, подозрительность, ощущение своей некомпетентности, чрезмерная самокритичность. При осуществлении деятельности, направленной на достижение успехов, лица с высоким уровнем тревожности чрезвычайно остро откликаются на информацию о своей неудаче, неэффективно работают в ситуациях, требующих напряжения усилий, в условиях временных ограничений, они в недостаточной степени сфокусированы на выполняемых действиях. Также тревожность опосредованно влияет на деятельность познавательных процессов, вследствие того, что у тревожного человека возрастает неуверенность в своей компетентности, в своих способностях, увеличивается количество неадекватных реакций. Таким образом, тревожность как состояние оказывает свое воздействие на поведение, деятельность, функционирование познавательных процессов высоко тревожных людей $[1,2]$. Поэтому коррекция личностной тревожности в школьном возрасте, в условиях психолого-педагогического сопровождения в образовательном учреждении, является важным фактором развития личности детей.

Представим результаты эксперимента, в ходе которого исследовались особенности проявлений личностной тревожности у обучающихся младшего подросткового возраста. В исследовании, проведенном под руководством автора, приняли участие пятиклассники одной из школ г. Северодвинска. В работе анализировались показатели личностной тревожности младших подростков, выделенные Е.Е. Ромицыной [5]: 1) общая тревожность, 2) тревога в отношениях со сверстниками, 3) тревога, связанная с оценкой окружающих, 4) тревога в отношениях с учителями, 5) тревога в отношениях с родителями, 6) тревога, связанная с успешностью в обучении, 7) тревога, возникающая в ситуациях самовыражения, 8) тревога, возникающая в 
ситуациях проверки знаний. Для изучения названных показателей использовались методики «Многомерная оценка детской тревожности (МОДТ)» [5] и методика «Незаконченные предложения», разработанная на основе методики Микляевой А.В. и Румянцевой П.В. [3]. Первая методика относится к методикам тестового типа, и предполагает согласие или несогласие с предложенными утверждениями, вторая относится к методикам дополнения, и предполагает свободные ответы испытуемых.

При анализе особенностей тревожности у младших подростков рассматривались проявления тревожности, имеющие непосредственное отношение к личностным особенностям ребенка; роль социальных контактов (со сверстниками, учителями и родителями) и роль ситуаций, связанных со школьным обучением в развитии тревожных реакций и состояний ребенка.

По результатам методики «МОДТ» можно отметить, что по всем показателям личностной тревожности у большинства обследованных подростков преобладает оптимальный (нормативный) либо низкий уровень тревоги. Для испытуемых характерен ровный эмоциональный фон, вера в себя, здравая оценка своих перспектив, угрожающими для них являются лишь ситуации, представляющие реальную опасность для жизни. Обучающиеся в состоянии адекватно ориентироваться на мнение других при оценке своих результатов, действий и мыслей; они уверенны и свободны, когда нужно выразить себя, свое мнение; непредвзято оценивают ситуацию и свою роль в ней. Аффективные проявления испытуемых отличаются адекватностью, у подростков получается поддерживать в основном спокойные отношения с большинством сверстников; при взаимодействии с учителями обучающиеся общаются с позиции дружеского взаимопонимания, они убеждены в том, что отношение педагогов к ним не зависит от получаемых ими отметок; отношения с родителями открытые, позитивные, доверительные, подростки могут говорить с ними на любые темы, не испытывая страха быть неверно понятыми, чувствуют себя свободно.

Одновременно с этим можно отметить, что среди обследованной группы детей были школьники, обнаружившие высокий уровень тревоги в следующих cферах:

- общая тревожность (четверть испытуемых): для них характерно некоторое снижение фона настроения, чувство неодобрения по отношению к себе, ощущение своей ущербности, внутреннее состояние напряжения, обеспокоенности, смятения, негативных ожиданий, растерянность относительно освоения новых видов деятельности, ощущение опасности для своей личности. Дети сохраняют эмоциональную стабильность и работоспособность в ситуациях, которые им знакомы, к которым они успешно адаптировались, но при осложнении ситуаций они теряют внутреннее равновесие. Поведение и взаимодействие с окружающими регулируются, прежде всего, эмоциями;

- тревога в отношениях с родителями (четверть испытуемых): взаимоотношения со взрослыми в семье характеризуются нестабильным эмоциональным фоном, ребенок постоянно насторожен и подозрителен при общении с обоими родителями или с одним из них, постоянно ожидает выговоров, замечаний, порицания или наказания со стороны родителей. Возможно, родители выдвигают по отношению к нему завышенные требования, используют в качестве метода воспитательного воздействия угрозы - что нарушает чувство защищенности ребенка в семье. Как правило, в таких семьях отсутствуют тесные эмоциональные связи между родителями и ребенком;

- тревога, возникающая в ситуациях проверки знаний (треть испытуемых): подростки отрицательно относятся к необходимости публично демонстрировать свои знания, особенно сильно переживают тревогу в ситуации контроля знаний в присутствии личностно значимой аудитории слушателей. Страх перед публич- 
ной демонстрацией знаний провоцирует чувство тревоги и неуверенности в себе. Такие дети боятся отвечать перед классом, особенно у доски. В этих ситуациях переживание тревоги сопровождается физиологическими изменениями (слабость, дрожь в руках и ногах, речевые нарушения). У тревожного подростка очень велика потребность в сканировании и контроле окружающего пространства, так как эмоциональное напряжение, спровоцированное тревогой, ведет к тому, что человек стремится охватить своим вниманием более широкий круг обстоятельств, чтобы вовремя увидеть и предупредить возможные осложнения так подросток реагирует на очень большой круг стимулов, могущих таить угрозу. Тревожность ухудшает эффективность решения познавательных задач, связанных с восприятием, памятью, научением, решением проблем.

Таким образом, по итогам анализа параметров оценки эмоциональноповеденческих расстройств тревожного спектра по методике «Многомерная оценка детской тревожности» можно сделать вывод о том, что большинство испытуемых из обследованной группы пятиклассников демонстрируют нормативный уровень тревожности, и лишь около четверти из них продемонстрировали повышенный уровень общей тревожности, а также тревожности в отношениях с родителями, и в ситуациях проверки знаний.

С помощью методики дополнения «Неоконченные предложения» планировалось выявление наиболее актуальных ситуаций для проявлений личностной тревожности. Методика позволяет выявить осознаваемые и неосознаваемые установки пятиклассников в отношении тех же показателей тревожности, которые изучались методикой «Многомерная оценка детской тревожности». Вероятно, вследствие проективного характера «Неоконченных предложений», результаты обследования детей несколько отличались от результатов предыдущей диагно- стики. Круг ситуаций, провоцирующих рост тревожности, расширился.

Наибольшее количество «эмоционально неблагополучных» ответов испытуемых по методике «Неоконченные предложения» было выявлено по показателю «общая тревожность» (примерно половина испытуемых); кроме этого, испытуемые обозначили ситуации, вызывающие состояние тревоги, по показателям «тревога в отношениях с родителями» (примерно половина детей), «тревога, возникающая в ситуациях самовыражения» (примерно половина детей), «тревога, возникающая в ситуациях проверки знаний» (примерно половина детей), «тревога, связанная с успешностью в обучении» (треть испытуемых); и около третьей части всех участников исследования отразили ситуации, вызывающие состояние тревоги, по показателям «тревога в отношениях со сверстниками» (треть испытуемых), «тревога, связанная с оценкой окружающих» (четверть испытуемых), «тревога в отношениях с учителями» (четверть испытуемых).

Примерно треть всех участников проведенного исследования демонстрируют высокий уровень личностной тревожности, имеющий непосредственное отношение к их личностным особенностям. В отношении показателя «общая тревожность» «эмоционально неблагополучные» ответы большинства испытуемых формулировались вокруг школьных проблем и переживаний. Дети отмечали, что обычно чувствовали себя в школе «...плохо; неважно; ужасно»; испытывали волнение во время выполнения контрольной работы, или, когда учитель объявляет оценки за контрольную работу, а также в тех ситуациях, когда их вызывают к доске. При описании ощущений в ситуациях, связанных с необходимостью самовыражения, пятиклассники отмечали, что им некомфортно выступать перед классом («...мне страшно; я стесняюсь»), отвечать на уроке («...я волнуюсь; я плохо себя чувствую»). Также около трети всех участников исследования испытывают тревогу, связанную с оценкой ок- 
ружающих: «Они думают, что...я плохая; ...я полный идиот»; «В общении с окружающими я...стесняюсь».

Достаточно большое количество участников исследования проявляют высокий уровень личностной тревожности, связанной с социальными контактами. Почти половина испытуемых испытывает тревогу в отношениях с родителями, в тех ситуациях, когда родители спрашивают у ребенка про школу («...я ухожу; мне становится страшно; я потею»); также дети беспокоятся, если родители «...ссорятся; ругают меня; спрашивают про оценки». Около трети всех участников исследования ощущают тревогу в отношениях со сверстниками: с одноклассниками, они чаще всего «...не общаются; не разговаривают; молчат; ссорятся»; предполагают, что одноклассники считают, что «...я дура; я другая; я глупая». Менее третьей части испытуемых ощущают тревогу в отношениях с учителями: дети «начинают волноваться, стесняются» когда видят учителя; или «немножко волнуются» когда учитель их спрашивает.

Значительное количество участников исследования демонстрируют высокий уровень личностной тревожности, связанной с ситуациями школьного обучения. Например, половина обследованных пятиклассников отметили тревогу, возникающую в ситуациях проверки знаний: это ситуация выполнения контрольной работы («...я нервничаю, я ужасно волнуюсь»); получение плохой оценки («...я расстраиваюсь, я плачу, я переживаю, я чувствую себя брошенной»); совершение ошибок («...я ругаю себя за них, мне чтото ударяет в душу, я переживаю»); ответ у доски («...я пытаюсь отнекаться, я боюсь, у меня дрожит рука»).

Таким образом, данные методики «Неоконченные предложения» позволили более точно обозначить особенности личностной тревожности младших подростков, охарактеризовать различные параметры оценки эмоциональноповеденческих расстройств тревожного спектра обучающихся пятого класса. В младшем подростковом возрасте происходит бурное развитие эмоциональной сферы, зачастую эмоциональные проявления подростков становятся практически неконтролируемыми ими. Это может быть связано с тем, что в подростковом возрасте общее возбуждение нарастает, а все виды торможения - ослабевают. Вследствие этого оказывается, что успокоиться подросткам теперь гораздо сложнее, чем ранее, в младшем школьном возрасте. Одни и те же жизненные события вызывают у подростков более яркий эмоциональный отклик, чем в начальной школе. Весь подростковый период характеризуется резкими перепадами настроения, повышенной возбудимостью, импульсивностью. Соответственно, расширяется круг тревогопорождающих ситуаций, специфики которых обучающиеся еще ясно не осознают, но их влияние на себя ощущают: это ситуации самовыражения, эмансипации от родителей и ощущение тревоги в связи с этим, отношения со сверстниками в аспекте публичности, оценки.

Результаты констатирующего эксперимента показали, что примерно у трети подростков, продиагностированных нами, повышенный и крайне высокий уровни личностной тревожности, обусловленный ситуациями школьного обучения. Тревогопорождающие ситуации связаны, также, с личностными особенностями испытуемых, и с социальными контактами подростков. Полученные данные могут свидетельствовать о наличии склонности к частым переживаниям тревоги в различных ситуациях у детей младшего подросткового возраста, что может вызывать трудности в социальном функционировании и адаптации испытуемых.

Следовательно, существует необходимость в проведении коррекционноразвивающей работы с младшими подростками по проблеме личностной тревожности. Мы предполагаем, что возможными направлениями преодоления личностной тревожности у младших подростков могут быть: расширение круга представлений об эмоциональной сфере через 
формирование представлений о ряде эмоциональных модальностей, о содержании эмоциональных переживаний, о социально-культурных нормах эмоционального выражения; формирование навыков разумного разрешения конфликтных ситуаций; развитие уверенности в себе и позитивного отношения к себе и окружающим; обучение детей приемам мышечной релаксации для снижения внутреннего напряжения. Одним из средств коррекции личностной тревожности у обучающихся пятого класса может быть психологическая игра, выступающая инструментом самопознания и жизненных экспериментов, решающая конкретные психологические задачи.
Психологическая игра работает с личностью как целостной структурой и имеет своей целью индивидуацию личности через осознание человеком актуального жизненного опыта. В условиях общеобразовательного учреждения психологическая игра позволяет педагогу-психологу создать условия для удовлетворения младшими подростками потребности в эмоциональных переживаниях, для эмоционального отреагирования; позволяет научить детей контролировать и регулировать свой внутренний мир, лучше понимать себя и других, увидеть, прочувствовать и принять новые модели поведения.

\section{СПИСОК ЛИТЕРАТУРЫ}

1. Астапов В. М. Тревожность у детей. М. : ПЕР СЭ, 2008. 160 с.

2. Малахова А. Н. Диагностика и коррекция тревожности и страхов у детей. СПб. : ООО «ИЗДАТЕЛЬСТВО «ДЕТСТВО-ПРЕСС», 2016. 208 с.

3. Микляева А. В., Румянцева П. В. Школьная тревожность: диагностика, профилактика, коррекция. СПб. : Речь, 2004. 248 с.

4. Прихожан А. М. Психология тревожности : дошкольный и школьный возраст. СПб. : Питер, 2009. $192 \mathrm{c}$.

5. Ромицына Е. Е. Методика «Многомерная оценка детской тревожности». Учебнометодическое пособие. СПб. : Речь, 2006. 112 с.

\section{REFERENCES (TRANSLITERATED)}

1. Astapov V. M. Trevozhnost' u detej. M. : PER SJe, 2008. $160 \mathrm{~s}$.

2. Malahova A. N. Diagnostika i korrekcija trevozhnosti i strahov u detej. SPb. : OOO «IZDATELSTVO «DETSTVO-PRESS», 2016. $208 \mathrm{~s}$.

3. Mikljaeva A. V., Rumjanceva P. V. Shkol'naja trevozhnost': diagnostika, profilaktika, korrekcija. $\mathrm{SPb}$. : Rech', 2004. 248 s.

4. Prihozhan A. M. Psihologija trevozhnosti : doshkol'nyj i shkol'nyj vozrast. SPb. : Piter, 2009. $192 \mathrm{~s}$.

5. Romicyna E. E. Metodika «Mnogomernaja ocenka detskoj trevozhnosti». Uchebnometodicheskoe posobie. SPb. : Rech', 2006. $112 \mathrm{~s}$.

Поступила в редакцию 16.03.2020.

Принята к публикации 18.03.2020.

Для цитирования:

Демидова И.Г. Особенности личностной тревожности у детей младшего подросткового возраста // Гуманитарный научный вестник. 2020. №2. C. 76-81. URL: http://naukavestnik.ru/doc/2020/2/Demidova.pdf 